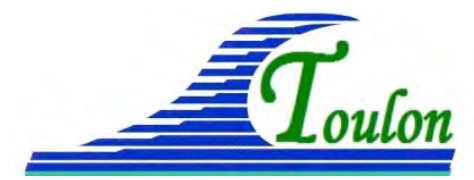
XIV $V^{e ̀ m e s}$ Journées Nationales Génie Côtier - Génie Civil Toulon, 29 juin au $1^{\text {er }}$ juillet 2016

DOI:10.5150/jngcgc.2016.057 C Editions Paralia CFL disponible en ligne - http://www.paralia.fr - available online

\title{
Idealized numerical investigation of the multi-scale interactions between an offshore wind turbine and the local oceanic dynamics
}

\author{
Tim NAGEL ${ }^{1}$, Julien CHAUCHAT ${ }^{1}$, Achim WIRTH ${ }^{2}$, Cyrille BONAMY ${ }^{2}$ \\ 1. Université Grenoble Alpes, LEGI, F-38000 Grenoble, France \\ tim.nagel@univ-grenoble-alpes.fr \\ 2. CNRS, LEGI, F-38000 Grenoble, France.
}

\begin{abstract}
:
In this contribution, a coupled two-dimensional idealized numerical model of the ocean and sediment layers, forced by an idealized offshore wind turbine wake is used to investigate the complex interactions between the wake, the ocean and the sediment. The turbine wake impacts the ocean surface and generates instabilities or vortex streets in the ocean for some parameter values. Shallow ocean layers (depth shallower than $15 \mathrm{~m}$ ) converge toward a laminar dynamics. When the water layer thickness is higher, large scale instabilities are generated, leading to a turbulent dynamics in the ocean layer. The size of the generated vortices in the ocean is controlled by the shallow wake parameter $\left(S=C_{D} D / H\right)$, in which $C_{D}$ is the bottom friction drag coefficient, $\mathrm{D}$ the wake diameter at the impact location and $\mathrm{H}$ the average depth of the ocean layer.
\end{abstract}

Keywords: Offshore wind turbines, Wake, Interactions, Ocean, Seabed, Dynamic, Renewable energy, Numerical modelling.

\section{Introduction}

Because of the rising need for sustainable energy and because wind energy is one of the few forms of renewable energy that can be harvested efficiently, many countries are planning and building offshore wind farms to increase the proportion of renewable energy in their energy mix. According to the European Wind Energy Association 2013 annual report (EWEA, 2013), the installed European capacity was of $5 \mathrm{GW}$ at the end of 2012. By 2030, the European offshore wind capacity could totalize $150 \mathrm{GW}$, corresponding to $14 \%$ of the actual EU's total electricity consumption. The growth of renewable energy is also strong in North America and in Asia (especially in China).

This worldwide wind energy development faces several ecological, technical and scientific issues. First of all, wind energy installations are not free from environmental impacts, principally on both coastal and marine ecosystems (a recent literature review on the subject is given by Dai (DAI et al., 2015) but also on the seabed evolution. The latter is affected by a scour process due to the pile presence, a phenomenon similar to that occurring at bridge piers (e.g BREUSERS et al., 1977; ROULUND et al., 2005 ). It has also been shown that local seabed elevation occurs in offshore wind farms (VAN 


\section{Thème 5 - Énergies et ressources marines}

DER VEEN et al., 2007). On a larger scale, the impact of wind farms on the European regional climate (VAUTARD et al., 2014) or on hurricanes (JACOBSON et al., 2014) have been studied recently, showing that the wind farms environmental impacts are an important questions nowadays. For economic reasons, trustworthy power predictions are needed before implementing a wind farm. According to ARCHER et al. (2014), research advancements in offshore observation, wind power forecasting, and turbulent wake loss would improve the models used and thus the power predictions for a given site.

To the best of our knowledges, the major part of atmospheric numerical models around wind turbines do not implement the ocean as a moving boundary but as an inert one with a constant roughness, the currents and the wave dynamics are thus neglected. Moreover, a recent numerical study from (MOULIN \& WIRTH, 2015) demonstrated that, at the sub-meso $(\mathrm{O}(10 \mathrm{~km}))$ scale, the oceanic currents are important in air-sea interactions and leave an imprint in the atmospheric dynamics.

Finally, if recent studies have shown the influence of large wind farms on the upper ocean circulation (BROSTRÖM, 2008) or on sediment suspension and transport around the pile structure, particularly for fine sediments (YIN et al., 2014), no work has been done on the atmospheric wake's impact on the ocean dynamics and on a possible feedback on the atmosphere. The purpose of the present paper is to answer the following question: What is the wake's impact on the ocean dynamic?

\section{Physical, mathematical and numerical model}

A detailed model description can be found in (NAGEL et al., 2015). The physical model consists in two superposed layers, a homogeneous shallow water ocean layer above a sediment bed layer, composed of cohesion-less particles. The atmospheric layer is not resolved and acts as a time constant external forcing (via a quadratic drag law with a constant drag coefficient $C_{D}$ ) and includes the velocity perturbations corresponding to the wake of a wind turbine.

The domain length are denoted as $\mathrm{Lx}(\mathrm{Lx}=2000 \mathrm{~m})$ and as $\mathrm{Ly}(\mathrm{Ly}=600-1000 \mathrm{~m})$ in the $\mathrm{x}$ and $\mathrm{y}$-direction, respectively. $\mathrm{H}(\mathrm{H}=10-60 \mathrm{~m})$ is the average depth of the ocean layer. The latter is forced by the local wind stress at its upper surface. The spatial variation of this wind stress incorporates the wake-profile of a wind turbine (JENSEN, 1983). The oceanic motion is only due to the wind forcing (i.e no large scale oceanic or tidal currents are considered) and induces a shear stress on the sediment bed layer. This stress and the seabed elevation are responsible for the coupling between both ocean and seabed layers. Periodic boundary conditions are used in both, the $\mathrm{x}$ and $\mathrm{y}$ directions.

The ocean dynamics is given by a single layer two dimensional Shallow Water (SW) equations which represents the flow averaged in the vertical direction. The seabed dynamics is given by the Exner equation (EXNER, 1920) and the (MEYER-PETER \& MÜLLER, 1948) bedload transport formula is used. 


\section{XIVìmes Journées Nationales Génie Côtier - Génie Civil \\ Toulon, 29 juin au $1^{\text {er }}$ juillet 2016}

Numerically, the overall model can be divided into two coupled modules, the hydrodynamic and the morphodynamic ones. Concerning the hydrodynamic module, where the SW equations for the ocean are solved, a second-order, centered finitedifference scheme is used for the spatial discretization, with a second-order RungeKutta scheme is used for the time discretization. The morphodynamic module solves the Exner equation using a NOCS (Non-Oscillatory Central Scheme) scheme as described by (JIANG et al., 1998; JIANG \& TADMOR, 1998).

\section{Results and discussion}

Figure 1 shows the vorticity fields $\left(\zeta=\partial_{x} V-\partial_{y} U\right)$ in the oceanic layer after 14 days of dynamics for 15, 20, 30 and $50 \mathrm{~m}$ of water layer thickness. The $15 \mathrm{~m}$ water layer thickness case (H15, figure 1, top panel) has a laminar dynamics and the vorticity is higher (or lower) at the wake boundaries showing that the wake boundaries are high shear-stress zones.

Figure 1 also shows that increasing the water layer thickness leads to a generation of oceanic instabilities. Indeed, for the 20 and 30 m water layer cases (H20 and H30, figure 1 , second and third panel from the top, respectively), vortices formed at the wake impact location continue to develop along the wake boundaries and form two distinct vortex streets. The eddies diameter $\left(\mathrm{D}_{\mathrm{e}}\right)$ and spacing $\left(\mathrm{L}_{\mathrm{e}}\right)$ depend on the water layer thickness too (see table 1 or figure 2 left panel, representing the variations of the eddies diameter for the different numerical simulations undertaken), both increasing with an increasing water layer thickness. When the latter exceeds $40 \mathrm{~m}$, the vortex streets interact leading to a domain-wide turbulence. For the $50 \mathrm{~m}$ case (H50, figure 1, fourth panel from the top) parts of the vortices are leaving the computational domain at one side and reenter at the opposite side due to the periodic boundary conditions. In order to ged rid of this confinement phenomenon, runs have been carried out with a wider domain of 1000 m (H20w, H30w, H40w, H50w, H60w and H60wCD3P4). From a physical point of view, the $1000 \mathrm{~m}$ width cases can be seen as a lesser densely packed wind farm. For the H50w case (figure 1, bottom panel), because the confinement is less important, the vortices shape is closer to the one observed for H30 than for H50. Finally, for all the water layer thicknesses were vortices are well formed (i.e from 30 to $60 \mathrm{~m}$ ), the presence of filaments inside the vortices is noteworthy. These filaments correspond to high shear-stress zones and appear initially at the wake boundaries. They are then advected in the $\mathrm{x}$-direction and rotated around the vortices center. The filaments intensity decreases as they are slowly reduced by viscosity. The confinement phenomenon can be highlighted thanks to the eddies diameter. Indeed, figure 2 (left) shows that for larger domain width, the vortices size is slightly lower for all the layer thicknesses from 30 to $50 \mathrm{~m}$. The largest difference between the confined and the nonconfined situations can be found when comparing runs $\mathrm{H} 40$ and H40w: if run $\mathrm{H} 40$ is similar to $\mathrm{H} 50$ in terms of vortices size, spacing and vorticity intensity, run H40w is 
closer to runs H30 and H30w. Qualitatively, two distinct vortex streets are formed in the domain for H40w rather than two interacting ones as for H40. The explanation comes from a combination of confinement and periodic boundary conditions: the confinement leads to a slight increase of the Reynolds shear stress, thus of the turbulence intensity and of the eddies size. For the confined domain, at $40 \mathrm{~m}$ water layer thickness, the eddies diameter becomes more important than the half domain width and the periodic boundary conditions allow part of the vortices to leave the domain and reentering on the opposite side. The vortices streets are thus perturbed, deviated by the reentering partial vortices and both vortex streets start to interact one with the other leading to a domainwide turbulence.

Table 1. Numerical experiments and main parameters results, $D_{r}$ is the rotor diameter $\Delta U$ is the velocity difference between outside and inside the wake at the impact location.

\begin{tabular}{|c|c|c|c|c|c|c|c|c|c|}
\hline $\begin{array}{l}\text { Run Name } \\
\text { Unit }\end{array}$ & $\begin{array}{l}H \\
\boldsymbol{m} \\
\end{array}$ & $\begin{array}{l}\text { Ly } \\
m\end{array}$ & $\begin{array}{l}u_{10} \\
m / s\end{array}$ & $\begin{array}{l}C_{D} \\
\left(10^{-3}\right) \\
\end{array}$ & $\begin{array}{l}D_{r} \\
m\end{array}$ & $\begin{array}{l}S \\
\left(10^{-2}\right)\end{array}$ & $\begin{array}{l}\Delta U \\
m / s \\
\end{array}$ & $\begin{array}{l}D_{e} \\
m\end{array}$ & $\begin{array}{l}L_{e} \\
m\end{array}$ \\
\hline H15 & 15 & 600 & 20 & 5 & 80 & 7.33 & 8.19 & - & - \\
\hline H2O & 20 & 600 & 20 & 5 & 80 & 5.50 & 8.19 & 120 & 500 \\
\hline H30 & 30 & 600 & 20 & 5 & 80 & 3.67 & 8.19 & 250 & 650 \\
\hline H40 & 40 & 600 & 20 & 5 & 80 & 2.75 & 8.19 & 550 & 1000 \\
\hline H50 & 50 & 600 & 20 & 5 & 80 & 2.20 & 8.19 & 550 & 1000 \\
\hline H60 & 60 & 600 & 20 & 5 & 80 & 1.83 & 8.19 & 550 & 1000 \\
\hline H60CD3Р4 & 60 & 600 & 20 & 3.75 & 80 & 1.375 & 8.19 & 550 & 1000 \\
\hline H20CD2P3 & 20 & 600 & 20 & 3.3 & 80 & 3.63 & 8.19 & 250 & 650 \\
\hline $\mathrm{H} 30 \mathrm{Dr}$ & 30 & 600 & 20 & 5 & 40 & 4.68 & 8.19 & 130 & 500 \\
\hline H2Ow & 20 & 1000 & 20 & 5 & 80 & 5.50 & 8.19 & 120 & 500 \\
\hline H30w & 30 & 1000 & 20 & 5 & 80 & 3.67 & 8.19 & 200 & 650 \\
\hline H40w & 40 & 1000 & 20 & 5 & 80 & 2.75 & 8.19 & 250 & 650 \\
\hline H50w & 50 & 1000 & 20 & 5 & 80 & 2.20 & 8.19 & 450 & 1000 \\
\hline H60w & 60 & 1000 & 20 & 5 & 80 & 1.83 & 8.19 & 580 & 1000 \\
\hline H60wCD3P4 & 60 & 1000 & 20 & 3.75 & 80 & 1.375 & 8.19 & 600 & 1000 \\
\hline H50U15 & 50 & 600 & 15 & 5 & 80 & 2.20 & 6.14 & 550 & 1000 \\
\hline H50U10 & 50 & 600 & 10 & 5 & 80 & 2.20 & 4.10 & 550 & 1000 \\
\hline
\end{tabular}

Figure 2 (left) also shows that once the domain-wide turbulent state is reached, the eddy size remains constant when increasing water layer thickness. Thus, for $60 \mathrm{~m}$ water layer thickness the non-confined eddies becomes larger than the confined ones. 


\section{XIV èmes Journées Nationales Génie Côtier - Génie Civil \\ Toulon, 29 juin au $1^{\text {er }}$ juillet 2016}

With different domain width, the computational variable allowing a quantitative characterization of the domain's turbulence for a given run is the Turbulent Kinetic Energy integral over the domain:

$T K E=1 / 2 H \iint_{A}\left(u^{\prime 2}+v^{\prime 2}\right) d A$

where $\mathrm{A}$ is the domain surface, and $u^{\prime}$ and $v^{\prime}$ are the velocity fluctuations, defined thanks to the Reynolds decomposition: an instantaneous quantity (such as u) is decomposed into its time-averaged $(\bar{u})$ and fluctuating $\left(u^{\prime}\right)$ part : $u=\bar{u}+u^{\prime}$.

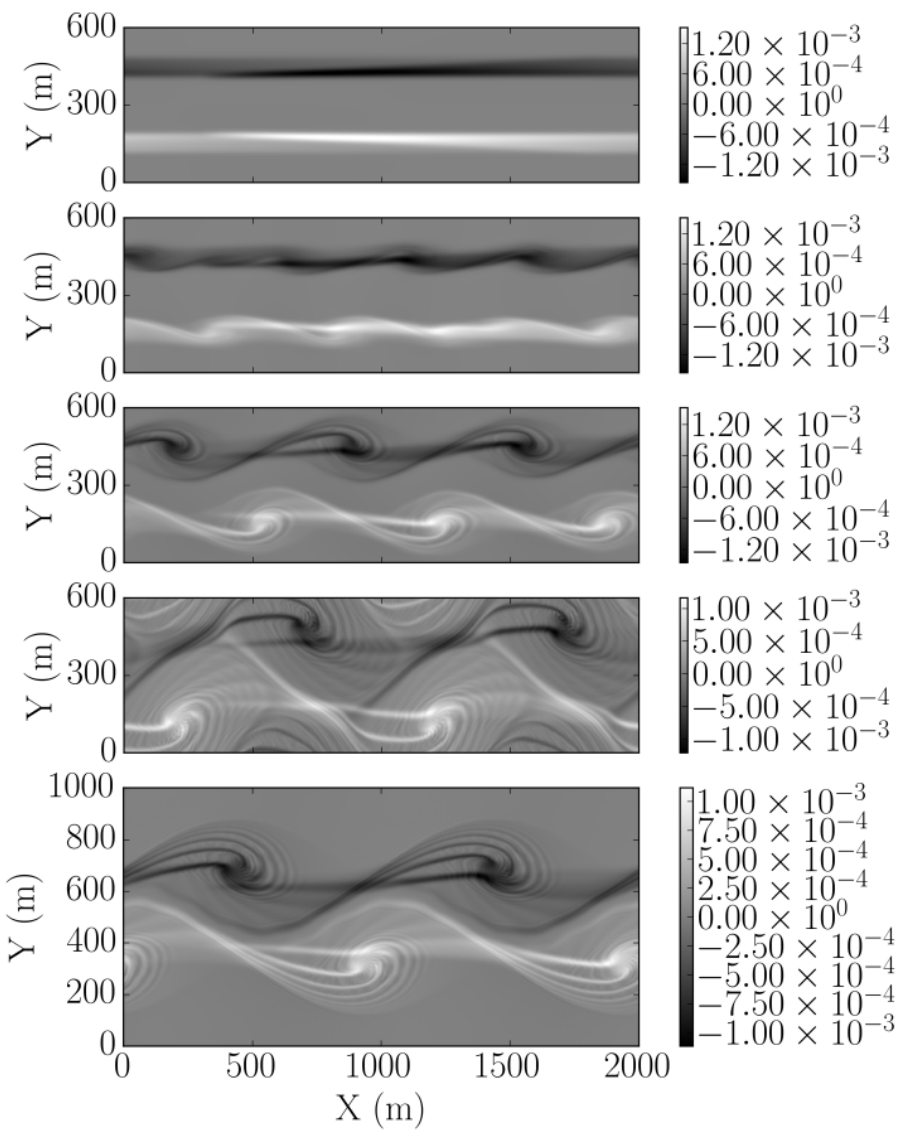

Figure 1. Bird view of $2 \mathrm{D}$ vorticity fields in the oceanic layer after 14 days of dynamics for H15, H20, H30, H50 and H5Ow (from top to bottom). Increasing the water layer

thickness leads to a generation of two types of oceanic instabilities, distinct and interacting ones, controlled by the wake stability parameter $S$.

Figure 2 (right) presents the normalized turbulent kinetic energy $\left(N T K E=T K E / u_{10}^{2}\right)$ versus the $\mathrm{S}$ parameter $\left(S=C_{D} D / H\right)$ for the runs described in the table $1 . \mathrm{S}$ is called the wake stability parameter (CHEN \& JIRKA, 1995 \& 1997) and compares the bottom friction to the advection. It clearly appears that, for a given domain width, the normalized TKE collapses as a function of the S parameter. The S dependency of the 


\section{Thème 5 - Énergies et ressources marines}

normalized TKE is shown by runs H20CD2P3 and H30Dr. Indeed, decreasing the bottom friction coefficient by a factor $2 / 3$ in order to conserve $S$ for the two cases with different water depth (H20CD2P3 and H30) gives very similar results on the normalized TKE but also on the oceanic vorticity field (not shown here). Furthermore, changing the $S$ parameter by changing the wake diameter at the impact location (D), which is done in run H30Dr, also keeps the normalized TKE value on the same curve. This shows that the $\mathrm{S}$ parameter is the control parameter of the oceanic turbulent dynamics, even if a dependency on the domain width remains. Furthermore, as the S parameter appears at the denominator in the bottom-friction term $\mathrm{G}$ in the SW equation, when increasing the water layer thickness, the $\mathrm{S}$ parameter is decreasing and the importance of bottom friction decreases, allowing for stronger instabilities. This explains the phenomenon observed in figure 1.

The $\mathrm{S}$ values obtained here are of the same order of magnitude than the ones corresponding to a vortex street regime for a porous plate in a steady flow (CHEN \& JIRKA, 1995). This shows that local oceanic velocity difference due to the wake impact is also one of the triggering processes for oceanic instabilities.
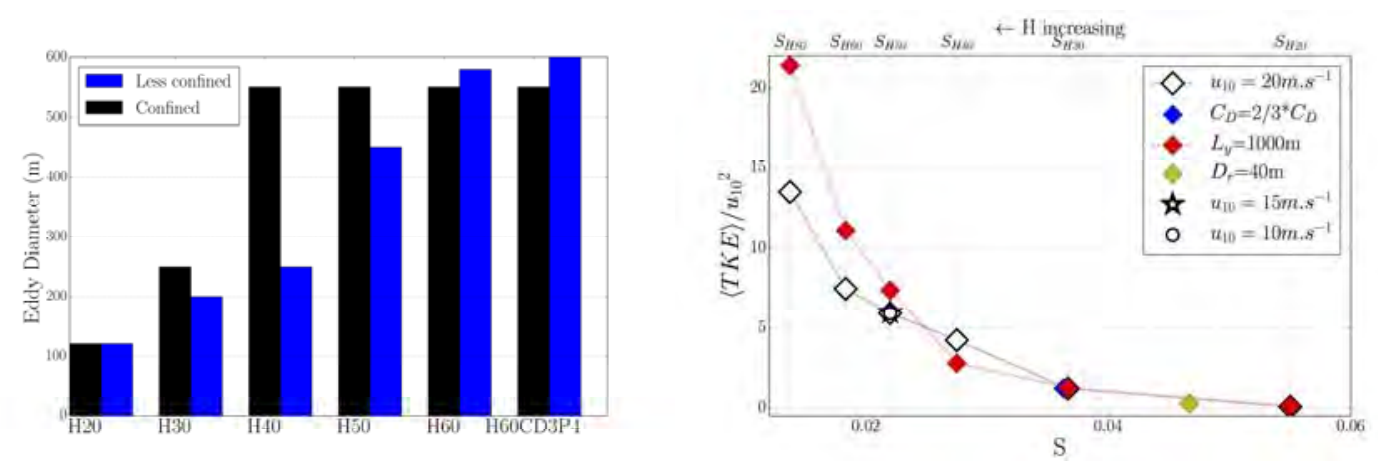

Figure 2. Comparison between the eddies diameter for the different numerical simulations undertaken (left) and plot of the normalized TKE as a function of the $S$ parameter (right). Empty diamond symbols correspond to less-confined case. The wake stability parameter is a control parameter of the oceanic turbulent dynamic, even if a dependency on the domain width remains.

Concerning the dependency on the domain width, it can be seen that for a $\mathrm{S}$ parameter corresponding to a $30 \mathrm{~m}$ water layer thickness (SH30) or less, the normalized TKE has the same values for both domain width. For S higher than SH30, the normalized TKE is affected by the confinement. At $40 \mathrm{~m}$ water layer thickness (SH40), because of the vortex streets destabilization (turbulence becomes domain-wide), the normalized TKE is higher for the confined case. At $50 \mathrm{~m}$, the turbulence becomes also domain-wide for the less confined situation, so the normalized TKE becomes higher than for the confined case. Finally, for increasing water depth, the less-confined situation values of the 


\section{XIV ${ }^{\text {èmes }}$ Journées Nationales Génie Côtier - Génie Civil \\ Toulon, 29 juin au $1^{\text {er }}$ juillet 2016}

normalized TKE remains higher and the difference with the more confined case will increase.

\section{Conclusions}

An idealized 2D numerical model has been proposed to study the impact of an offshore wind turbine wake on the ocean dynamics. The results show that the turbine wake has an impact on both ocean and sediment bed layers. Turbine wake impact on the ocean surface can generate instabilities and vortex streets. Size and spacing between these vortices are controlled by the wake stability parameter $\left(S=C_{D} D / H\right)$. When $S$ is decreased, large scale instabilities are more easily generated, leading to a domain wide turbulence state in the ocean. Furthermore, the results have also highlighted the important role of the confinement (the spacing of wind turbines in a farm) in the generation of instabilities. A law for the non-dimensional eddy viscosity, obtained from the turbulence simulations, as a function of the $S$ parameter can be proposed and further used in RANS simulations. This will allow to parametrize the ocean dynamic response to wind turbine wake forcing in non eddy resolving simulations.

\section{Acknowledgment}

We thank the Institut Carnot Energies du Futur and the Observatoire des Sciences de l'Univers de Grenoble (OSUG) for their financial support. All the computations presented in this paper were performed using the Froggy platform of the CIMENT infrastructure (https://ciment.ujfgrenoble.fr), which is supported by the Rhône-Alpes region (GRANT CPER07-13 CIRA) and the Equip@Meso project (reference ANR-10EQPX-29-01) of the programme Investissements d'Avenir supervised by the Agence Nationale pour la Recherche.

\section{References}

ARCHER C. L., COLLE B. A., MONACHE L., et al. (2014). Meteorology for coastal/offshore wind energy in the United States: recommendations and research needs for the next 10 years. Bulletin of the American Meteorological Society, April, pp 515519. http://dx.doi.org/10.1175/BAMS-D-13-00108.1

BREUSERS H., NICOLLET G., SHEN H. (1977). Local scour around cylindrical piers. Journal of Hydraulic Research, Vol. 15(3), 211252. http://dx.doi.org/10.1080/00221687709499645

BROSTRÖM, G. (2008). On the influence of large wind farms on the upper ocean circulation. Journal of Marine Systems, Vol. 74(1), 585-591. http://dx.doi.org/10.1016/j.jmarsys.2008.05.001

CHEN D., JIRKA G. H. (1997). Absolute and convective instabilities of plane turbulent wakes in a shallow water layer. Journal of Fluid Mechanics, Vol. 338, pp 157-172. http://dx.doi.org/10.1017/s0022112097005041 
Thème 5 - Énergies et ressources marines

DAI K., BERGOT A., LIANG C., XIANG W. N., HUANG Z. (2015). Environmental issues associated with wind energy A review. Renewable Energy, Vol. 75, pp 911-921. http://dx.doi.org/10.1016/j.renene.2014.10.074

EWEA - European Wind Energy Association- (2013). Deep water, the next step for offshore wind energy. Study report, $50 \mathrm{p}$.

EXNER F. M. (1920). Zur Physik der Dunen. Akad. Wiss Wien. Part IIa, Bd. 129.

JACOBSON M. Z., ARCHER C.L., KEMPTON W. (2014). Taming hurricanes with arrays of offshore wind turbines. Nature Climate Change, Vol. 4(3), pp 195-200. http://dx.doi.org/10.1038/nclimate2120

JIANG G.S., TADMOR E. (1998). Nonoscillatory central schemes for multi dimensional hyperbolic conservation laws. SIAM Journal on Scientific Computing, Vol. 19(6), pp 1892-1917. http://dx.doi.org/10.1137/S106482759631041X

JIANG G. S., LEVY D., LIN C. T., OSHER S., TADMOR, E. (1998). High-resolution nonoscillatory central schemes with nonstaggered grids for hyperbolic conservation laws. SIAM Journal on Numerical Analysis, Vol. 35(6), pp 2147-2168. http://dx.doi.org/10.1137/S0036142997317560

JENSEN N.O. (1983). A note on wind generator interaction. Risø-M-2411, Risø National Laboratory.

MEYER-PETER E., MÜLLER R. (1948). Formulas for bed-load transport. IAHR.

MOULIN A, WIRTH A. (2014). A Drag-Induced Barotropic Instability in Air-Sea Interaction. Journal of Physical Oceanography, Vol. 44, pp 733-741. http://dx.doi.org/10.1175/JPO-D-13-097.1

NAGEL T., CHAUCHAT, J., WIRTH A. (2015). Investigation of the multi-scale interactions between an offshore wind turbine wake and the ocean-sediment dynamics in a idealized framework. E-proceedings of the 36th IAHR World Congress.

ROULUND A., SUMER B., FREDSØE J., MICHELSEN J. (2005). Numerical and experimental investigation of flow and scour around a circular pile. Journal of Fluid Mechanics, Vol. 534, pp 351-401. http://dx.doi.org/10.1017/S0022112005004507

SUMER M. (2007). Mathematical modelling of scour: A review. Journal of Hydraulic Research, Vol. 45(6), pp 723-735. http://dx.doi.org/10.1080/00221686.2007.9521811

VAN DER VEEN H.H., HULSCHER S., PEREZ LAPENA B. (2007). Seabed morphodynamics due to offshore wind farms. RCEM 2007.

VAUTARD R., THAIS F., TOBIN I., BREON F.-M., DEVEZEAUX DE LAVERGNE J.-G., COLETTE A., YIOU P., RUTI P.M. (2014). Regional climate model simulations indicate limited climatic impacts by operational and planned european wind farms. Nature communications, 9 p. http://dx.doi.org/10.1038/ncomms4196

YIN Y., CHRISTIE E., LI M., MOULINEC C., EMERSON D. (2014). 3D morphological impact modelling of offshore wind farms using LES and HPC. Coastal Engineering Proceedings. 1(34), sediment-48. http://dx.doi.org/10.9753/icce.v34.sediment.48 